\title{
Os registros gráficos no contexto do Ensino de Ciências por Investigação: em foco o Programa de Residência Pedagógica
}

\author{
Alice Helena Bertola*, Tatiana Schneider Vieira de Moraes ${ }^{\star *}$
}

\section{Resumo}

No contexto do Programa de Residência Pedagógica foram organizadas ações que possibilitaram a discussão do Ensino de Ciências por Investigação (ENCl) nos anos iniciais do Ensino Fundamental como uma ferramenta para a construção de habilidades científicas. Com essa perspectiva, este trabalho objetiva investigar se o aluno, ao se engajar em atividades de cunho investigativo, pode aprimorar o processo de produção de textos escritos. O percurso metodológico foi estruturado incluindo uma revisão bibliográfica e uma pesquisa qualitativa, com um caráter de estudo de caso. Os dados foram categorizados de acordo com a técnica de Análise de Conteúdo, a qual evidenciou a necessidade de ampliação de estudos teóricos e práticos que fomentam discussões acerca do ENCI no âmbito da leitura e da escrita. Os registros, provenientes de ações investigativas, podem favorecer a inserção da criança em processos associados ao fazer científico, como a necessidade de escrever e comunicar seus achados, compreendida como uma atividade inerente ao trabalho investigativo.

Palavras-chave: Ensino de Ciências por Investigação; Ensino Fundamental, Programa de Residência Pedagógica.

* Licenciada em Pedagogia pela Faculdade de Filosofia e Ciências - UNESP de Marília. Pós-graduada em Psicopedagogia e Neurociências pela Universidade Paulista - UNIP. Coordenadora Pedagógica na Escola Waldorf Cora Coralina de Marília. E-mail: alice.bertola97@hotmail.com

* Doutora em Educação pela Faculdade de Educação - USP. Docente do Curso de Pedagogia vinculada ao Departamento de Didática da Faculdade de Filosofia e Ciências da UNESP de Marília. E-mail: tatiana.moraes@ unesp.br 


\section{Introdução}

Este trabalho manifesta algumas inquietações e questionamentos à prática escolar, com ênfase nas metodologias de cunho investigativo afetas ao Ensino de Ciências. Essas indagações impulsionaram o desenvolvimento desta pesquisa no contexto do Programa de Residência Pedagógica (PRP) - Edital CAPES no 06/2018 - (BRASIL, 2018), no qual foi constituído um grupo de trabalho formado por quatro residentes bolsistas, uma residente voluntária, uma professora preceptora (escola básica) e a docente orientadora (universidade). Esse grupo teve por objetivo discutir, entre outras perspectivas, a inserção do Ensino de Ciências por Investigação (ENCI) na etapa do Ensino Fundamental (EF), bem como a introdução do aluno em processos autênticos de investigação científica, engajando-os em tarefas de resolução de problemas, levantamento e teste de hipóteses, sistematização e contextualização do conhecimento, visando uma efetiva aproximação entre o universo da ciência e a linguagem científica.

O engajamento em atividades investigativas é apontado por Sasseron (2015) como um caminho para a promoção da Alfabetização Científica (AC) na escola básica, processo reconhecido como um dos objetivos centrais do Ensino de Ciências e possível de ser efetivado desde os primeiros anos de escolarização. A autora complementa que o foco principal da AC é o envolvimento do aluno com a cultura científica e com os processos de tomada de decisões individuais e coletivas.

Com a compreensão de que o ENCI pode representar um caminho possível para as propostas que almejam a Alfabetização Científica, emerge a questão central dessa investigação: Como que as atividades investigativas podem contribuir para o envolvimento dos alunos com processos de leitura e escrita, no contexto do Programa de Residência Pedagógica?

Com essa perspectiva, este trabalho objetiva investigar se o aluno, ao se engajar em atividades de cunho investigativo, registra os fenômenos que observa. Dessa forma, buscamos compreender a importância da escrita articulada às atividades investigativas como uma ferramenta inerente ao trabalho de construção de conhecimento em um processo investigativo no contexto do Programa de Residência Pedagógica. Essas ações foram efetivadas no PRP com o subprojeto Licenciatura em Pedagogia "Leitura e escrita em diferentes áreas de conhecimento" a partir da articulação entre a leitura, a escrita e os pressupostos do Ensino de Ciências por 
Investigação, bem como a constituição de um grupo de trabalho específico para o desenvolvimento dessa proposta.

O PRP é uma iniciativa da CAPES que integra a Política Nacional de Formação de Professores do Ministério da Educação, visando intensificar a formação prática nos cursos de licenciatura e promover a integração entre a educação básica e a educação superior (BRASIL, 2019). Com esse propósito, o PRP preenche algumas lacunas urgentes que são relativas à necessidade de um Projeto Político Pedagógico explícito para a formação docente e coloca o estágio como um possível articulador desse processo formativo. Nóvoa (2013) argumenta que o professor se forma na escola, dentro da sua profissão, atuantes no espaço da sala de aula e construindo reflexões sobre o seu próprio trabalho.

A partir das ações efetivadas pelos residentes na escola campo vinculada ao Programa de Residência Pedagógica, esta pesquisa apresenta como hipótese inicial a ideia de que quando o aluno é incentivado a buscar explicações científicas, resultantes das observações que realiza, das diferentes interações e situações de aprendizagem que vivencia, emerge a necessidade de pesquisar e registrar o processo ao qual está envolvido, favorecendo assim o desenvolvimento da leitura e da escrita no contexto investigativo.

\section{Pressupostos teóricos}

Pesquisas recentes sobre o Ensino de Ciências vêm apontado a importância de ressignificar o processo de ensino e a adoção de práticas que promovam, dentre outras abordagens didáticas, os processos investigativos em sala de aula, possibilitando a inserção do aluno na construção do seu conhecimento, almejando a formação de um cidadão crítico (SASSERON, 2015).

O Ensino Ciências por Investigação é apontado como sendo uma estratégia de proposta didática que privilegia a problematização, na qual o aluno é o sujeito do conhecimento e a sua construção é realizada a partir de interações com outros atores e com o meio circundante (CARVALHO, 2013).

Sasseron e Carvalho (2008) apontam sobre a necessidade de um ensino de Ciências que permita aos alunos trabalhar e discutir problemas envolvendo fenômenos naturais como forma de introduzi-los ao universo das Ciências e não mais ensinando uma Ciência "acabada" e "pronta" em que não há espaço para discussões acerca de 
seus fenômenos, mas somente a sua operacionalização em exercícios tradicionalizados. As autoras também evidenciam sobre a importância do desenvolvimento de atividades em sala de aula que possibilitem argumentações entre os alunos e o professor em momentos de investigação, nas quais os alunos são conduzidos a formular hipóteses, criar argumentos para defendê-las, propondo afirmativas e reunindo fatos que direcionam a explicação das ações investigadas (SASSERON; CARVALHO, 2011).

Com essa perspectiva, a efetivação de propostas que abordam o ENCI desde os anos iniciais se faz necessária para que o aluno tenha acesso a um conjunto de ações que caracterizam a cultura científica, tais como: formular hipóteses, desenvolver habilidades, explicar fenômenos, argumentar e comunicar seus achados (SASSERON, 2015).

Na compreensão dos estudos que enfatizam essa abordagem em sala de aula, Zômpero e Labarú (2011), destacam a partir de uma análise de cinco pesquisas que o desenvolvimento de atividades investigativas, apesar de apresentar denominações e procedimentos variados na literatura, possuem alguns elementos centrais que podem ser identificados pela presença de: problema real a ser analisado pelos alunos; processo de emissão de hipóteses; planejamento para a realização do processo investigativo, incluindo a busca por informações (experimentais ou bibliográficas), que auxiliam na resolução do problema; interpretação dos dados e, por fim, a comunicação dos estudos realizados. Carvalho (2013) também argumenta sobre a potencialidade do trabalho investigativo em sala de aula, propondo abordagens metodológicas que dialogam com as propostas analisadas no trabalho de Zômpero e Laburú (2011), na medida em que propõe: resolução de problemas investigativos; levantamento, teste e organização de hipóteses; resolução do problema de investigação; análise e interpretação dos dados; construção de relações causais; explicação; socialização dos conhecimentos construídos e registros.

Nesse cenário, a criação de um ambiente investigativo em aulas de Ciências, por meio de Sequências de Ensino Investigativas, pode conduzir os alunos à interação com elementos da cultura científica vinculados com a linguagem, dentre eles a escrita, efetivado pelos registros produzidos pelas crianças durante as atividades e a leitura, concretizada pela seleção de textos de sistematização do conhecimento vinculados ao tema de estudo da SEI. 
Para que essa proposta seja inserida de forma plena no cenário escolar, as atividades investigativas devem, portanto, ser desenvolvidas com questões problematizadoras, mas que estas tragam aspectos da vida dos alunos, ou seja, problemas reais e desafiadores que podem ser vivenciados e refletidos no contexto escolar, com a orientação do professor. É necessário que os alunos se interessem pelo problema a ser investigado, de forma a se sentirem motivados a resolvê-lo (ZANON; FREITAS, 2007; ZOMPERO; LABARU, 2011).

Com essa perspectiva, compreende-se como atividade investigativa, conforme salientado por Carvalho (2013), aquela em que o trabalho do aluno não se restringe apenas à manipulação de objetos e observação dos mesmos, mas que ao contrário, apresenta características do fazer científico, ou seja, permite ao aluno refletir, discutir, explicar, testar suas ideias e suposições bem como relatar sobre a atividade investigada. A autora aponta que alguns elementos constitutivos da SEI contribuem para instigar os alunos a partir de uma situação problema, fazendo-os pensar e propor soluções para a mesma, incluindo o uso de leituras de textos, atividades experimentais, debates, atividades em grupo, produção de desenhos e textos, entre outros. A problematização do conteúdo científico também contribui para a reflexão, para o desenvolvimento do pensamento crítico, capaz de auxiliar na resolução de problemas e para a construção de conhecimentos, de forma muito mais consistente.

Em síntese, é indispensável que a escola desperte e desenvolva, nos alunos, o interesse pela leitura e pela escrita, a partir de contextos investigativos e com o uso de diferentes linguagens para ampliar o raciocínio e a argumentação do aluno, permitindo que escrevam corretamente e desenvolvam as habilidades de interpretar, compreender, tornando-o um leitor crítico, argumentativo e independente.

\section{Pressupostos metodológicos}

No contexto do Programa de Residência Pedagógica, a pesquisa foi estruturada em duas fases. A primeira fase foi constituída por uma pesquisa bibliográfica para a caracterização de um corpus de trabalhos, difundidos por teses e dissertações, cujo o escopo central foi estabelecer uma relação entre as atividades investigativas e os processos de leitura e escrita. Os trabalhos foram selecionados nas seguintes bases de dados: Biblioteca Digital Brasileira de Teses e Dissertações (BDTD) e Catálogo de Teses e Dissertações da CAPES, sem recorte de tempo. 
Os descritores de busca foram utilizados com operadores booleanos OR e AND com as seguintes combinações: ("ensino por investigação" OR "ensino de ciências por investigação" OR "atividades investigativas") AND leitura e ("ensino por investigação" OR "ensino de ciências por investigação" OR "atividades investigativas") AND escrita. Apesar da busca ter sido realizada de forma separada, os dados obtidos, tanto para leitura quanto para escrita, foram tratados conjuntamente, pois se relacionam com o escopo desta investigação.

A análise dos dados obtidos foi realizada mediante a organização de eixos temáticos de análise, a saber: 1) A escrita / leitura e o Ensino de Ciência por Investigação no contexto das intervenções com alunos e 2) A escrita / leitura e o Ensino de Ciência por Investigação no contexto da formação de professores ou dos materiais pedagógicos.

$\mathrm{Na}$ segunda fase desta pesquisa, foram empreendidas ações na escola campo, vinculada ao Programa de Residência Pedagógica, com o objetivo de articular os elementos do ENCI com a escola básica, no contexto da leitura e da escrita, apresentando um enfoque predominantemente qualitativo. Para tanto, foi estruturada uma Sequência de Ensino Investigativa (SEI), pautada nos pressupostos de Carvalho (2013).

Lüdke e André (2004, p. 18) apontam que uma pesquisa de natureza qualitativa "se desenvolve numa situação natural, é rica em dados descritivos, tem um plano aberto e flexivel [...] focalizando a realidade de forma complexa e contextualizada". Os dados gerados e selecionados para a análise, no contexto desta investigação, circunscrevem uma abordagem de estudo de caso, na medida em que ocorre a busca pela compreensão da observação detalhada em cooperação com os participantes (BOGDAN; BIKLEN, 1994). Os dados gerados também permitem a análise e interpretação de fatos e fenômenos exatamente como ocorrem no real, oriundos da produção de dados, embasada numa fundamentação teórica consistente, objetivando compreender e explicar o problema pesquisado, conforme orientam Lüdke e André (2004). Foram recolhidos os registros gráficos das crianças como forma de instrumento de coleta de dados.

O percurso metodológico insere-se na organização de uma Sequência de Ensino Investigativa (SEI) (CARVALHO, 2013), intitulada de "Seres vivos", a qual foi aplicada aos alunos do $3^{\text {o }}$ ano do Ensino Fundamental de uma escola municipal do interior paulista. A constituição da SEI foi um processo oriundo de encontros recorrentes entre a docente orientadora e as alunas residentes do Programa. A 
temática foi sugerida pela professora da turma do $3^{\circ}$ ano, por ser um tópico do conteúdo programático a ser ministrado. A professora da turma também fez sugestões e adequações na estrutura final da SEI, considerando o conhecimento dos alunos em questão, bem como agregando outros valores a esse processo formativo.

Os princípios éticos foram adotados com o envio e recolhimento de assinatura do Termo de Consentimento Livre e Esclarecido (TCLE) dos pais dos alunos, bem como os nomes dos sujeitos e da escola-campo foram preservados.

\section{Análise de dados}

Os dados obtidos nas duas fases desta investigação serão apresentados nas seções seguintes, organizadas para o tratamento e análise dos dados bibliográficos (3.1) e dos dados empíricos (3.2). Os dados bibliográficos foram analisados com base na técnica da análise de conteúdo (BARDIN, 2011), na qual foram identificadas as semelhanças entre os estudos para que fosse possível estabelecer agrupamentos por meio de categorias temáticas, sendo identificadas duas categorias de análise: 1) Escrita / leitura e o Ensino de Ciência por Investigação no contexto das intervenções com alunos e 2) Escrita / leitura e Ensino de Ciência por Investigação no contexto da formação de professores ou dos materiais pedagógicos.

Os dados empíricos também foram analisados com base na técnica de análise de conteúdo (BARDIN, 2011). A partir da aplicação da SEI foram obtidos dados na forma de registros gráficos das crianças (desenho e escrita), analisados com base em eixos temáticos, a saber: 1) Registros de classificação e 2) Registros de atividade experimental. Em decorrência de algumas dificuldades apresentadas pelos discentes, importa destacar que não foi possível categorizar todos os registros.

\section{Dados bibliográficos}

Na BDTD, foram encontrados o total de 32 trabalhos associados com o termo leitura e 58 trabalhos associados ao termo escrita. Desse total, apenas 07 trabalhos (06 dissertações e 1 tese) atenderam aos critérios de inclusão, que permitiu articular a perspectiva investigativa em Ensino de Ciências com os anos iniciais do Ensino Fundamental no contexto da escrita e da leitura. No Banco de Teses e Dissertações da CAPES, foram encontrados o total de 09 trabalhos associados com 
o termo leitura e 16 trabalhos associados ao termo escrita. Desse total, apenas 03 dissertações atenderam aos mesmos critérios de inclusão.

Após a organização e tratamento dos dados, iniciou-se o processo de análise a partir da leitura na íntegra dos trabalhos selecionados, com o intuito de identificar as semelhanças entre os estudos e estabelecer possíveis agrupamentos. Essa escolha foi feita com base nas estratégias utilizadas nas pesquisas e, com essa perspectiva, verificou-se a presença de duas categorias distintas (Quadro 1).

Quadro 1: Categoria de análise e distribuição dos trabalhos localizados.

\begin{tabular}{|c|c|c|c|}
\hline Categoria & Descrição & $\begin{array}{c}\text { Número de } \\
\text { artigos alocados }\end{array}$ & Autores/ano \\
\hline $\begin{array}{l}\text { Escrita/leitura e o En- } \\
\text { sino de Ciência por In- } \\
\text { vestigação no contexto } \\
\text { das intervenções com } \\
\text { alunos }\end{array}$ & $\begin{array}{l}\text { Categoria que descreve as inter- } \\
\text { venções realizadas com as crianças } \\
\text { com o intuito de estabelecer rela- } \\
\text { ções entre os elementos da cultura } \\
\text { científica e da alfabetização na lín- } \\
\text { gua materna. }\end{array}$ & 8 & $\begin{array}{l}\text { Trevisani (2019); } \\
\text { Hilário (2018); } \\
\text { Zerlottini (2017); } \\
\text { Silva (2017); } \\
\text { Zocoler (2016); } \\
\text { Almeida (2015); } \\
\text { Nunes (2013); } \\
\text { Oliveira (2009). }\end{array}$ \\
\hline $\begin{array}{l}\text { Escrita/leitura e o En- } \\
\text { sino de Ciência por In- } \\
\text { vestigação no contexto } \\
\text { da formação de profes- } \\
\text { sores ou dos materiais } \\
\text { pedagógicos }\end{array}$ & $\begin{array}{l}\text { Categoria que descreve as ações } \\
\text { realizadas com os professores com } \\
\text { o intuito de potencializar a aproxi- } \\
\text { mação com o Ensino de Ciências } \\
\text { por Investigação e com os materiais } \\
\text { pedagógicos facilitadores do ensino } \\
\text { da leitura e da escrita }\end{array}$ & 2 & $\begin{array}{l}\text { Melo (2017); } \\
\text { Pinto (2012). }\end{array}$ \\
\hline
\end{tabular}

Fonte: dados de pesquisa (2019).

Com essa perspectiva, os trabalhos alocados em cada categoria são apresentados e analisados nos tópicos seguintes.

\section{A escrita/leitura e o Ensino de Ciência por Investigação no contexto das intervenções com alunos:}

Os trabalhos localizados e enquadrados nessa categoria apresentam um eixo comum composto pela proposição de atividades investigativas ou Sequência de Ensino Investigativo para turmas do Ensino Fundamental I, envolvendo conteúdos científicos. De modo geral, os dados coletados, na forma de registros escritos, foram analisados com a perspectiva de avaliar as contribuições do ensino investigativo para o processo de escrita dos alunos. 
Nesse contexto, Silva (2017) analisou os registros escritos de alunos de $4^{\circ}$ e $5^{\circ}$ anos após uma intervenção didática com uma SEI e identificou três categorias de registros a saber: relatos de experimento científico; relatos de experiência vivida; relatos híbridos. A autora concluiu que os relatos de experimentos, gênero textual típico da cultura científica, bem como os relatos híbridos apresentaram mais indícios da interação dos alunos com a cultura científica e evidenciaram, de forma mais relevante, o uso da escrita, enquanto elemento do fazer ciência. Com essa mesma perspectiva, Zocoler (2016) objetivou investigar de que maneira a prática da produção de textos de forma contextualizada, durante atividades investigativas, poderia auxiliar os estudantes a compreenderem eventos científicos do cotidiano e a produzirem textos mais coerentes e coesos. A análise dos dados foi pautada na identificação dos indicadores de Alfabetização Científica, na análise da estrutura de argumentos e nos elementos que tornam um texto coerente e coeso. Os resultados evidenciaram que é possível integrar Ciências e Língua Portuguesa em um constante trabalho de articulação entre a $\mathrm{AC}$ e o aprendizado da produção de textos escritos, de modo síncrono e efetivo. A autora destaca que os elementos constitutivos do processo de planejamento de atividades investigativas, proporcionam condições para que o aluno fale e sinta a necessidade de divulgar o que aprendeu, legitimando a escrita como um processo inerente ao trabalho investigativo, coadunando com as ideias de Silva (2017).

O trabalho de Trevisani (2019), pautado nos pressupostas da Teoria Histórico-Cultural, também utiliza a produção textual dos alunos, bem como os desenhos, com o objetivo de evidenciar o processo de construção de conceitos científicos desencadeados pelos alunos a partir do envolvimento com atividades investigativas. A produção textual com o intuito de verificar as aproximações com a escrita científica também foi o foco dos estudos de Almeida (2015). Os resultados apontam que os alunos do $5^{\mathbf{o}}$ ano do EF conseguiram relatar as atividades propostas e alguns apresentaram, na escrita, a construção de uma relação causal para o fenômeno físico estudado, bem como utilizaram palavras e expressões que se aproximaram da linguagem científica. Almeida (2015) também destaca que esse processo pode expressar indícios da construção do raciocínio científico em consonância com os estudos de Nunes (2013) que aponta para o desenvolvimento de habilidades cognitivas avançadas a partir do engajamento em atividades investigativas. A análise dos registros, neste contexto, 
também identificou a escrita como um elemento correspondente às intenções do ato comunicativo.

Oliveira (2009) apresentou uma relação de interdependência entre os registros orais e escritos dos alunos, produzidos ao término das atividades investigativas. A autora propôs que a discussão oral ajuda os alunos no momento de registro escrito, sendo que esse último tem o importante papel de socializar informações e de aumentar o conhecimento sobre o tema trabalhado. Ademais, a autora constatou que a fala é uma importante mediadora entre o pensamento e a escrita. Com essa mesma perspectiva, Hilário (2018) identificou que os relatos escritos produzidos ao final das atividades propostas é uma ferramenta eficiente que estimula as crianças na oralidade, leitura e produção escrita, contribuindo para o processo de alfabetização em linguagem, a partir de uma abordagem investigativa.

Em um contexto diferente, Zerlottini (2017) avaliou o potencial das aulas de Ciências com caráter investigativo, com o objetivo de promover a autonomia dos alunos e a criatividade na produção de poemas. A aplicação de uma SEI pautada na temática sobre o ciclo da água permitiu que os alunos refletissem sobre as Ciências, elaborando suas ideias de uma forma pouco comum para a disciplina: em versos, envolvendo-os em um processo criativo e autoral. Ao evidenciar a produção de poemas nas aulas de Ciências, a autora expõe a importância da escrita, assim como Zocoler (2016), em um processo de articulação bastante favorável entre as aulas de Língua Portuguesa e as outras disciplinas, sobretudo, a de Ciências, potencializando o processo de aquisição de linguagem científica.

\section{A escrita/leitura e o Ensino de Ciência por Investigação no contexto da formação de professores ou dos materiais pedagógicos}

Os dois trabalhos alocados nessa categoria possuem um eixo comum evidenciado pelas ações voltadas à formação de professores no âmbito do Ensino de Ciências por Investigação que consideram os processos de leitura e a escrita em suas propostas. Nesse contexto, Pinto (2012) objetivou compreender como ocorre a aproximação dos elementos das Ciências Naturais pela Literatura Infantil, bem como analisar o uso desse gênero pelos professores dos anos iniciais do Ensino Fundamental. A coleta de dados foi efetivada por meio de análise documental de livros de Literatura Infantil disponíveis aos alunos dos anos iniciais do EF e de entrevistas com 6 professores 
desse segmento de ensino. A autora aponta que o uso didatizado da Literatura Infantil é consistente, desde que os professores sejam levados a pensar na problemática e busquem subsídios teóricos a fim de elaborarem estratégias de leitura. Os temas relacionados ao Ensino de Ciências são representativos na Literatura Infantil e, por isso, apresentam-se promissores para novas análises.

Em outro contexto, Melo (2017) caracterizou a concepção do Ensino de Ciências da Natureza proposto no Pacto Nacional pela Alfabetização na Idade Certa (PNAIC) com o intuito de identificar as contribuições e limites dessa proposta para a disciplina em questão. A pesquisa empregada foi do tipo documental, com abordagem qualitativa, a partir dos cadernos de formação continuada do PNAIC publicados em 2012, 2014 e 2015. O PNAIC propõe direitos inovadores de aprendizagem na área de Ciências da Natureza, mas as práticas de ensino apresentadas pouco oportunizaram momentos reais, capazes de potencializar substancialmente o planejamento e reflexões críticas sobre as práticas de ensino de Ciências. As propostas para a prática docente, geralmente, não estabelecem relações diretas com os direitos de aprendizagem e vinculam nas atividades a concepção tradicional e, por vezes, o ensino via redescoberta. Nesse contexto, o ensino de Ciências precisa ir além da simples memorização das informações veiculadas em textos e exposição dos docentes. É preciso promover o acesso efetivo dos discentes em práticas de investigação, nas quais haja oportunidade efetiva de compreensão dos conhecimentos científicos e tecnológicos.

A análise dos dados bibliográficos revela, para a primeira categoria, a organização de situações de ensino investigativas que são promotoras de ações de leitura e, sobretudo de registro. Alguns trabalhos objetivaram caracterizar esses registros, bem como evidenciar sua importância no ato de comunicar as atividades investigativas realizadas pelas crianças e registrar o processo de construção de conceitos científicos. Ademais, foi evidenciado também possibilidades de integração entre as disciplinas de Ciências e Língua Portuguesa, no contexto do ENCI. Sobre esse aspecto, Brandi e Gurgel (2002) apontam a importância do processo de leitura e escrita no Ensino de Ciências, com vistas à introdução da criança à cultura científica. Entretanto, essas autoras destacam a necessidade de formação de professores como sendo um elemento essencial para inserção desses aspectos nos anos iniciais do EF, fato que corrobora com os poucos trabalhos representativos da segunda categoria. 
Após esse processo de tratamento e análise dos dados da pesquisa bibliográfica, a seção seguinte objetiva descrever e discutir os dados produzidos na escola vinculada ao Programa de Residência Pedagógica.

\section{Dados coletados na escola campo}

Com base no referencial teórico e metodológico do Ensino de Ciências por Investigação foi estruturada uma SEI, a qual foi aplicada na escola campo como atividade de regência do Programa de Residência Pedagógica. De acordo com a portaria CAPES 259/2019 (BRASIL, 2019, art. 3ํ) "o PRP tem por finalidade promover a experiência de regência em sala de aula aos discentes da segunda metade dos cursos de licenciatura, em escolas públicas de educação básica, acompanhados pelo professor da escola". Com essa perspectiva, a proposta foi pautada na organização de uma Sequência de Ensino Investigativa (CARVALHO, 2013) que compreende um conjunto de atividades intencionalmente planejadas, envolvendo um conteúdo escolar e organizada de modo a privilegiar as discussões dos alunos durante a resolução de problemas, permitindo o levantamento de hipóteses, a sistematização do conhecimento e o registro das atividades realizadas.

A SEI em questão foi intitulada de "A Classificação dos Seres vivos" (Quadro 2), envolvendo o conteúdo relacionado aos reinos animal e vegetal e teve o objetivo de compreender como o Ensino de Ciências por Investigação, pautado na Alfabetização Científica, pode contribuir para o aprimoramento da produção de textos escritos. A sequência foi estruturada com 6 aulas, sendo que o problema de investigação proposto às crianças foi: Como pode classificar os seres vivos?. Compreendemos que as questões problematizadoras devem ser amplas e envolver a abordagem Ciência-Tecnologia-Sociedade-Ambiente (CTSA), mas nem sempre essa articulação é possível. Coaduamos com a ideias apresentadas por Sasseron (2015, p. 57) nas quais os "processos de discussão e resolução de problemas ligados às ciências são trabalhados em situações de ensino", ou seja, temáticas científicas podem ser estruturadas em problemas e propostas em situações didáticas, intencionalmente organizadas para este propósito. 
Quadro 2: SEl aplicada na turma do $3^{\circ}$ ano do EF.

\begin{tabular}{|l|l|}
\hline \multicolumn{2}{|l|}{ TíTULO: “A Classificação dos Seres vivos” } \\
\hline Problema de investigação: Como podemos classificar os seres vivos? \\
\hline AULA 1 & $\begin{array}{l}\text { Conversando sobre os seres vivos e não vivos do mundo - apresentação do problema } \\
\text { orientador da investigação "Como podemos classificar os seres vivos?, passeio pes- } \\
\text { quisa e registro (Foto 1). }\end{array}$ \\
\hline AULA 2 & $\begin{array}{l}\text { Conhecendo o grupo dos artrópodes: Leitura de livro, atividade de classificação dos } \\
\text { artrópodes e registro das ações (Foto 2). }\end{array}$ \\
\hline AULA 3 & $\begin{array}{l}\text { Classificando o reino animal - Atividade de classificação com imagens de diferentes } \\
\text { animais (habitat, locomoção, alimentação, cobertura do corpo e reprodução), circuito } \\
\text { de animais com observação em pequenos grupos (hamster, peixe, gato, lula, camarão, } \\
\text { minhoca, larvas de besouro, tartaruga, pintinho) (Foto 3). }\end{array}$ \\
\hline AULA 4 & $\begin{array}{l}\text { Classificação do reino vegetal - Passeio pesquisa para coleta de folhas, leitura de texto } \\
\text { sobre classificação das folhas e registro (Foto 4). }\end{array}$ \\
\hline AULA 5 & $\begin{array}{l}\text { Evidenciando o processo da fotossíntese - Realização da atividade experimental e } \\
\text { investigativa sobre a fotossíntese, leitura de texto e registro (Foto 5). }\end{array}$ \\
\hline AULA 6 & $\begin{array}{l}\text { Conversando sobre classificação e aplicação do jogo - Atividade utilizando chave dico- } \\
\text { tômica de classificação de animais e plantas, seguida de leitura de texto sobre cadeia } \\
\text { alimentar e realização de atividade lúdica sobre "Jogo da cadeia alimentar" e registro } \\
\text { (Foto 6). }\end{array}$ \\
\hline
\end{tabular}

Fonte: elaborado pelas autoras.

No conjunto das descrições das ações efetivadas, são apresentadas algumas fotos dos elementos destacados nas aulas de 1 à 6 que compuseram a SEI do $3^{\circ}$ ano: 


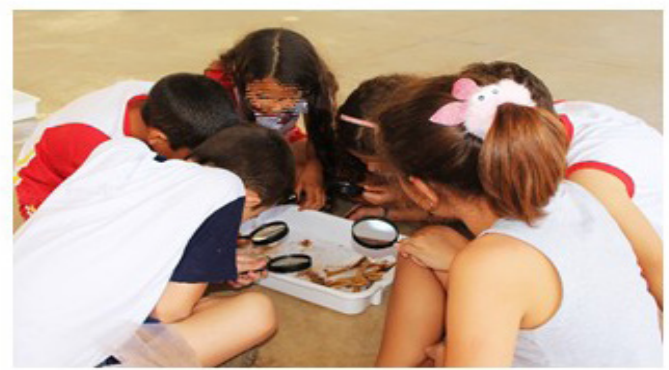

Foto 1: Alunos analisando a coleta realizada no passeio pesquisa.

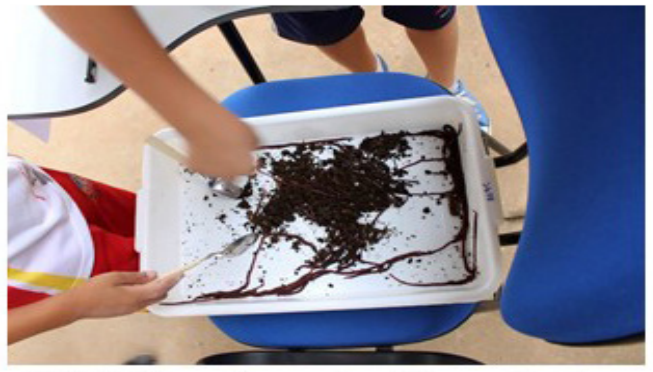

Foto 3: Alunos observando minhocas durante o circuito de animais.

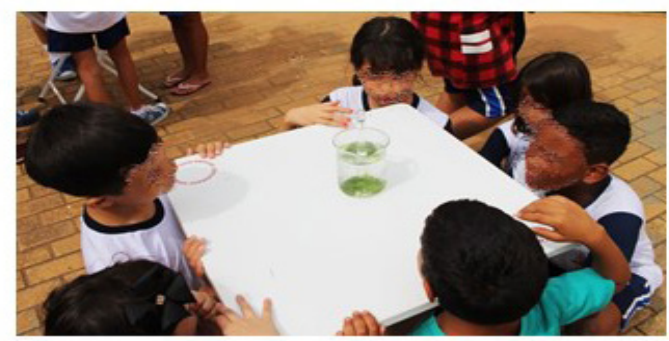

Foto 5: Alunos observando o experimento da fotossintese.

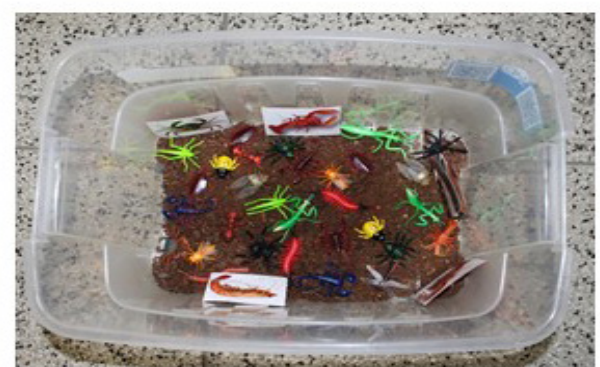

Foto 2: Caixa utilizada na atividade de classificação dos artrópodes.

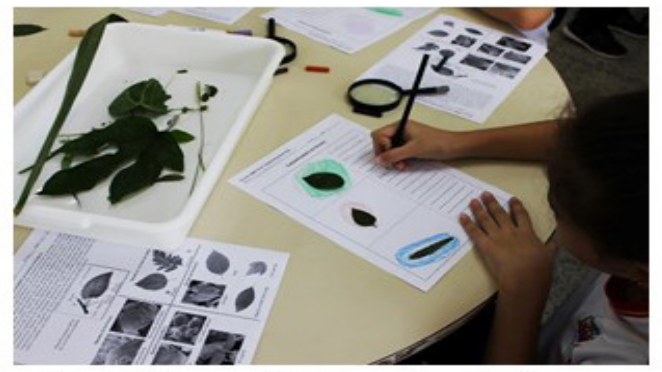

Foto 4: Aluna analisando a coleta de folhas e fazendo o registro utilizando o texto base.

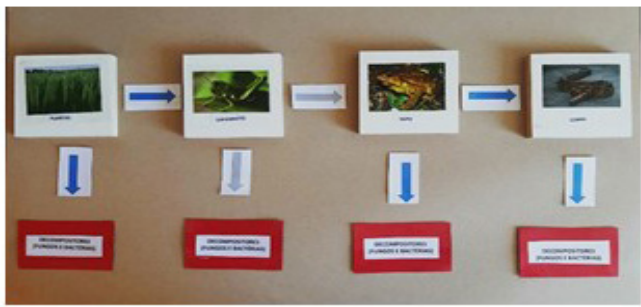

Foto 6: Jogo Cadeia Alimentar organizado por um grupo de alunos.

A organização da SEI e sua consequente aplicação na escola campo vinculada ao PRP representa uma etapa importante do processo de imersão dos lincenciandos no cotidiano escolar com possibilidades de reflexão sobre os pressupostos teóricos do Ensino por Investigação em articulação com as práticas observadas e experimentadas, as quais foram efetivadas pela regência da SEI em sala de aula. Portanto, este estudo apresenta capilaridade tanto para a instrumentalização teórica e prática dos licenciandos envolvidos no contexto da formação inicial e dos professores da escola básica que passam a vivenciar novas propostas metodológicas em um contexto de 
formação continuada. Com esta perspectiva, as crianças também são beneficiadas com as atividades que são desenvolvidas, enriquecendo seu reportório cultural, aqui representado pelas ações relativas às ciências.

Nesse sentido, Moraes, Lima e Carvalho (2021) argumentam sobre a necessidade do professor criar condições objetivas e efetivas para o fomento das ações investigativas com as crianças, estimulando diferentes formas de linguagem com o intuito de mobilizar o pensamento, a memória, a atenção, a percepção, dentre outras qualidades especificamente humanas.

Ao término das atividades propostas, foi solicitado que os alunos realizassem os registros gráficos das ações vivenciadas por eles, os quais foram analisados com base nas categorias indicadas. A presença da categoria "Registros de classificação" ficou evidente na escrita produzida pela aluna após a separação dos materiais encontrados no passeio pesquisa no qual ela apresenta suas hipóteses sobre a classificação dos seres vivos (animais e plantas) e dos seres não vivos (Figura 1).

A figura 2 evidencia outro tipo de registro que também foi alocado nessa categoria "Registros de classificação". Neste caso, a criança classifica as folhas com base nas informações fornecidas por meio da leitura de um texto e das discussões realizadas entre a residente e os alunos. Importa destacar que o texto lido anteriormente e que fomentou a realização dessa atividade, foi sistematizado pelas alunas residentes com a supervisão da professora orientadora e apresentou questões relativas à classificação das folhas incluindo imagens, texto escrito e referências. 


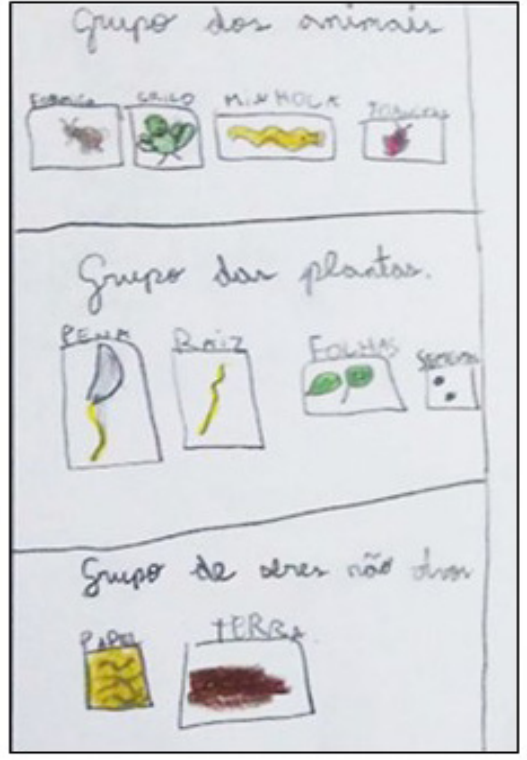

Figura 1: Registro de uma aluna sobre o 'Passeio Pesquisa'. Legenda: Grupo dos animais (formiga, grilo, minhoca e joaninha); Grupo das plantas (pena, raiz, folhas e sementes); Grupo de seres não vivos (papel e terra).

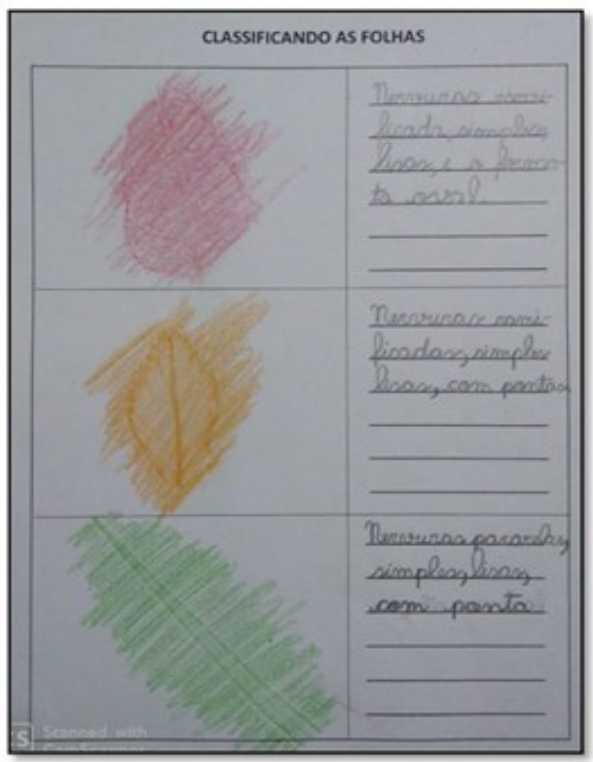

Figura 2: Registro sobre classificação das folhas: técnica de sombreamento com lápis. Classificação das folhas de acordo com o texto e as discussões realizadas em aula.

A análise dos dados indica que, dentre as hipóteses da criança a pena foi classificada como um elemento do "Grupo das plantas", ou seja, do reino vegetal. Essa confusão é plausível para a idade uma vez que esses conhecimentos estão sendo construídos e consolidados pela criança e observar a pena como um elemento isolado pode dificultar a visualização do animal como um todo. Jiménez-Aleixandre, Bugallo Rodríguez e Duschl (2000) apresentam um conjunto de operações epistemológicas (indução, dedução, causalidade, definição, classificação, apelos, consistências e plausibilidade) que orientam a construção dos argumentos utilizados pelos alunos, os quais contribuem para a inserção na cultura científica e no entendimento dos diferentes aspectos das ciências, bem como no engajamento em discussões que envolvam temas científicos. Nesse entendimento, os autores apontam a classificação como uma operação epistemológica para se fazer ciência na medida em que possibilita o agrupamento de objetos ou organismos de acordo com critérios pré-estabelecidos. 
Sasseron e Carvalho (2008) propõem os Indicadores de Alfabetização Científica, nos quais a "classificação de informações" (p. 338) integra um conjunto de indicadores relacionados ao trabalho com os dados obtidos em uma investigação. As autoras apontam que o ato de classificar informações "constitui-se em um momento de ordenação dos elementos com os quais se está trabalhando procurando uma relação entre eles" (p. 338).

Como apontado pelos autores, classificar não é um único elemento do processo de Alfabetização Científica, mas representa uma habilidade importante que somada a tantas outras em um processo investigativo, pode contribuir para elevar os níveis de consciência das crianças e o envolvimento crescente com a aquisição de significados da linguagem das Ciências.

Na sequência das análises, a discussão se voltou para os registros realizados após as ações práticas e investigativas durante o desenvolvimento da SEI.

Após a realização do experimento sobre a fotossíntese as crianças fizeram o registro dessa atividade. A categoria "Registro de atividade experimental" fica evidente na análise desse registro como mostra a Figura 3.

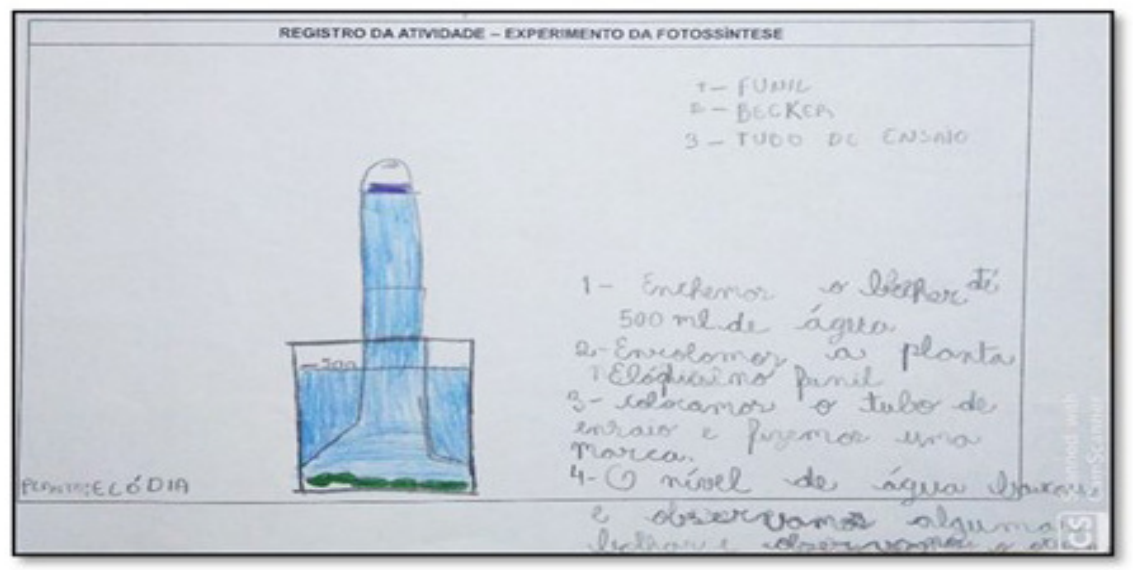

Figura 3: Registro de uma aluna sobre o 'Passeio Pesquisa'. Legenda: 1 - Funil; 2Becker; 3 - Tu bo de ensaio. 1 - Enchemos o Becker até $500 \mathrm{ml}$ de água; 2 - Enrolamos a planta elódea no funil; 3- Colocamos o tubo de ensaio e fizemos uma marca; 4- O nível de água baixou e observamos algumas bolhas e observamos o oxigênio. Planta: Elódia.

O registro apresenta vários elementos que foram utilizados para a elaboração do experimento da fotossíntese. A criança descreve os passos realizados durante o desenvolvimento da experiência, incluindo aspectos relacionados às conclusões finais 
observadas pelo grupo. Importa destacar que apesar de ser um registro individual, a criança reforça o caráter coletivo da construção do experimento quando utiliza todos os verbos na terceira pessoa do plural.

Silva (2017) aponta que os registros classificados como "relatos de experimentos" representam um gênero textual típico da cultura científica e apresentaram mais indícios da interação dos alunos com a cultura científica uma vez que evidenciaram, de forma mais relevante, o uso da escrita, enquanto elemento do fazer científico.

Ademais a criança utiliza a linguagem do desenho e a linguagem escrita como complementares. Com essa perspectiva, Derdyk (2004) aponta que as linguagens verbal e gráfica participam de uma natureza mental, com suas especificidades e particularidades, mas cada uma, à sua maneira, contribui para a formação de uma ideia, imagem ou conceito.

Após análises dos registros produzidos por alunos ao término das aulas de Ciências, cujo o foco foi a resolução de um problema, Oliveira e Carvalho (2005) e Sasseron e Carvalho (2010) apontam que as crianças utilizam os desenhos como apoio para auxiliar a compreensão das ideias apresentadas no texto escrito ou complementar alguma informação que não conseguem expressar de forma escrita.

A criança elabora seu gênero do discurso (BAKHTIN, 2003), seu conteúdo, suas escolhas para construir sua escrita. $\mathrm{O}$ registro de atividade experimental é uma ação inerente à cultura científica, comumente utilizado na ciência para o registro do conhecimento científico e, portanto, precisa ser apropriado na escola, local propício para a articulação entre a linguagem escrita e a científica informada.

O engajamento com situações de registros, decorrentes de ações intencionalmente planejadas em um contexto investigativo podem favorecer a inserção da criança em processos associados ao fazer científico, representados no recorte desta pesquisa pela necessidade da criança escrever e comunicar seus achados.

\section{Considerações finais}

As ações vinculadas ao Programa de Residência Pedagógica tiveram como foco o ensino, sobretudo o Ensino de Ciências por Investigação, mas também possibilitaram a inserção do aluno residente em contextos amplos de articulação entre o ensino, a pesquisa e a extensão. 
O percurso de desenvolvimento desta pesquisa permitiu caracterizar, a partir da análise dos dados bibliográficos, a prevalência dos estudos que articulam a leitura/ escrita com o Ensino de Ciências por Investigação no contexto das intervenções com as crianças dos anos iniciais do Ensino Fundamental. Esses trabalhos apontam a relevância do engajamento das crianças na resolução de situações-problemas como disparador para a linguagem escrita, permeada de elementos da ciência, bem como o registro uma ferramenta inerente ao processo de comunicação e construção de conceitos científicos e uma possibilidade de integração entre as disciplinas de Ciências e Língua Portuguesa, no contexto do ENCI. Importa destacar que foram encontrados apenas dois estudos que articulam a escrita/leitura com o ENCI no contexto da formação de professores e dos materiais pedagógicos, indicando a necessidade de discussão e ampliação de trabalhos que possam favorecer a instrumentalização teórico e prática de professores da rede básica de ensino. De todo modo, foi possível perceber a escassez de material, consolidado no conjunto de teses e dissertações, sobre esta interface de estudo, sugerindo um campo com possibilidades de expansão de conhecimentos.

Com a perspectiva de estruturar e aplicar uma SEI, no contexto da regência do Programa de Residência Pedagógica, também foi proposto o desenvolvimento de atividades investigativas que pudessem fomentar o envolvimento dos alunos com processos de leitura e escrita.

Sobre este aspecto, importa destacar, em um primeiro momento o protagonismo dos residentes na construção a aplicação da SEI no contexto do programa, resvalando em ações de formação inicial de professores que, pela configuração do PRP, também impactam a formação continuada. No conjunto dessas ações, as crianças da escola campo são favorecidos, uma vez que se beneficiam das atividades propostas, intencionalmente planejadas, com o intuito de articular a promoção da escrita a partir do fomento às ações investigativas.

Nesse sentido, a SEI trabalhada motivou e envolveu os alunos com as estratégias de resolução de problemas, levantamento de hipóteses, comunicação e compreensão de fenômenos. O desenvolvimento dessa sequência possibilitou a coleta de dados através das representações dos registros dos alunos, pois ao propor uma tarefa de registrar uma situação de aprendizagem, o repertório do aluno se expande de modo significativo e esses registros podem expressar evidências do conhecimento adquirido durante as atividades realizadas. 
Ademais, o registro desempenha uma função de linguagem, compreendendo significados e sentidos precisos, que não se configuram apenas como uma representação gráfica, mas constituem-se em uma estratégia de pensamento, a qual precisa ser estimulada pelo professor, como uma habilidade constitutiva do processo de aprendizagem, mas que precisa ser aprendida pela criança.

Com essa perspectiva, a SEI trabalhada, contemplou atividades de leitura e escrita relacionadas com atividades de experimentação, pesquisa, atividades lúdicas, sistematização e discussão de conceitos estudados. A relação entre essas diferentes estratégias se apresenta como uma proposta potente para o processo de ensino e aprendizagem, na medida em que mobiliza diversas formas do pensamento e possibilita o engajamento dos alunos com diferentes estratégias de ensino relacionados à mesma temática e vinculadas ao contexto da leitura e da escrita.

O trabalho investigativo, organizado com esses elementos, proporcionou também a construção de espaços e ações potentes para o protagonismo da criança durante $o$ processo de formação de conceitos científicos de forma contextualizada. O Ensino de Ciências por Investigação potencializa a criação de um ambiente investigativo nas escolas, que possibilita a condução e mediação das crianças no processo simplificado do trabalho científico para que possam, gradualmente, se envolver com a cultura científica e se apropriar, integralmente, da linguagem das Ciências.

Assim, integrar Ciências e linguagens nos primeiros anos do Ensino Fundamental pode fomentar o desenvolvimento de habilidades essenciais para o processo de ensino e aprendizagem para essas e outras áreas do conhecimento, fortalecendo a importância das Ciências Naturais no processo formativo das crianças.

\section{Agradecimentos}

As autoras agradecem à CAPES pelo apoio financeiro, à escola campo vinculada ao Programa de Residência Pedagógica, à professora e aos alunos da turma do $3^{\circ}$ ano de 2019. 


\section{Graphic records in the context of Inquiry-Based Teaching Science: focusing on the Pedagogy Residence Program}

\section{Abstract}

In the context of the Pedagogical Residency Program, actions were taken to enable the discussion of Inquiry-Based Teaching Science (IBTS) in the early years of Elemenatry School to act as a tool for the construction of scientific skills. With this perspective, this paper aims to investigate if the student, by engaging in investigative activities can improve the production process of written texts. The methodological path was structured including a bibliographical review and a qualitative research, acting as a study case. All data were categorized using the Content Analysis technique, which has evidenced the need to expand theoretical and practical studies that encourages discussions about IBTS in the scope of reading and writing. The records, originated from investigative actions may favor the child's insertion in processes associated with scientific activities, such as the need to write and communicate its findings, acknowledged as an activity inherent of investigative work.

Keywords: Inquiry-Based Teaching Science; Elementary School; Pedagogical Residence Program.

\section{Referências}

ALMEIDA, K. S. Ensino por Investigação: Identificando Elementos de Escrita Científica na Produção Textual de Alunos do Ensino Fundamental. 2015. 124 f. Dissertação (Mestrado), Departamento de Ciências da Educação, Universidade Estadual de Santa Cruz, Ilhéus, Bahia, 2015.

BARDIN, L. Análise de Conteúdo. São Paulo: Edições 70, 2011.

BAKHTIN, M. Estética da criação verbal. São Paulo: Martins Fontes, 2003.

BOGDAN, R. C.; BIKLEN, S. K. Investigação qualitativa em educação: uma introdução à teoria e aos métodos. Porto: Porto Editora, 1994.

BRANDI, A. T. E.; GURGEL, C.M.A. A Alfabetização Científica e o Processo de Ler e Escrever em Séries Iniciais: Emergências de um Estudo de Investigação-Ação. Ciência \& Educação, v. 8, n. 1, p. 113-125, 2002.

BRASIL. EDITAL CAPES nº 06/2018. PROGRAMA DE RESIDÊNCIA PEDAGóGICA. Chamada Pública para apresentação de propostas no âmbito do Programa de Residência Pedagógica, 2018. Disponível em: https://www.gov.br/capes/pt-br/acesso-a-informacao/acoes-e-programas/ educacao-basica/programa-residencia-pedagogica. Acesso em: 10 jun 2021.

BRASIL. PORTARIA № 259, DE 17 DEZEMBRO DE 2019. Dispõe sobre o regulamento do Programa de Residência Pedagógica e do Programa Institucional de Bolsa de Iniciação à Docência (PIBID). Disponível em: https://www.in.gov.br/en/web/dou/-/portaria-n-259-de-17-dezembro-de-2019-234332362. Acesso em: 10 jun 2021. 
CARVAlHO, A. M. P. O Ensino de Ciências e a proposição de Sequências de Ensino Investigativas. IN: CARVALHO, A. M. P. Ensino de Ciências por Investigação: Condições para implementação na sala de aula. São Paulo: Cengage Learning, 2013.

DERDYK, E. Formas de pensar o desenho: desenvolvimento do grafismo infantil. 3. ed. São Paulo: Scipione, 2004.

HILÁRIO, T. W. Vai equilibrar? As contribuições da sequência de ensino por investigação para alfabetização em linguagem no ensino de ciências. 2018, 159 f. Dissertação (Mestrado) - Instituto Federal de Educação, Ciência e Tecnologia de Goiás. Jataí, Goiás, 2018.

JIMÉNEZ ALEIXANDRE, M. P.; BUGALLO RODRÍGUEZ, A.; DUSCHL, R. A. Doing the lesson or doing science: argument in high school genetics. Science Education, Hoboken, v. 84, n. 6, p. 757-792, 2000.

LÜDKE, M.; ANDRÉ, M. E. D. A. Pesquisa em educação: abordagens qualitativas. São Paulo: EPU, 2004.

MELO, S. C. S. Ensino de ciências da natureza no Pacto Nacional pela Alfabetização na Idade Certa. 2017. 180 f. Dissertação Mestrado) - Programa de Pós-Graduação em Educação da Universidade Federal de Pernambuco, Recife, Pernambuco, 2017.

MORAES, T. S. V.; LIMA, E. A.; CARVALHO, A. M. P. Em defesa da atividade de professores e crianças: reflexões sobre a iniciação às ciências na educação infantil. Perspectiva, v. 39, n. 1, p. 1-19, 2021.

NÓVOA, A. Nada substitui um bom professor: Propostas para uma revolução no campo da formação de professores. In: GATTI, B. A. (et tal). Por uma política nacional de formação de professores. 1ª ed. São Paulo: Editora Unesp, 2013. p. 199-210.

NUNES, M. B. T. Uma investigação sobre o desenvolvimento da escrita em aulas de ciências no quinto ano do ensino fundamental. 2013. 117 f. Dissertação (Mestrado) - Centro de Educação e Ciências Humanas, Universidade Federal de São Carlos, São Carlos, São Paulo, 2013.

OLIVEIRA, C. M. A. Do discurso oral ao texto escrito nas aulas de ciências. 2009. $234 \mathrm{f}$. Tese (Doutorado) - Faculdade de Educação, Universidade de São Paulo, São Paulo, 2009.

OLIVEIRA, C. M. A.; CARVALHO, A. M. P. Escrevendo em aulas de Ciências. Ciência e Educação, v. 11, n. 3, p. 147-166, 2005.

PINTO, A. A. Aproximações entre literatura infantil e ensino de ciências: um estudo de práticas pedagógicas de professoras dos anos iniciais do ensino fundamental. 2012. 184 f. Dissertação. Faculdade de Ciência e Tecnologia. Universidade Estadual Paulista, UNESP, Presidente Prudente, São Paulo, 2012.

SASSERON, L. H.; CARVALHO, A. M. P. Almejando a Alfabetização Científica no Ensino Fundamental: A proposição e a procura de indicadores do processo. Investigações em Ensino de Ciências. Porto Alegre, v. 13, n. 3, p. 333-352, 2008.

SASSERON, L. H.; CARVALHO, A. M. P. Escrita e desenho: análise de registros elaborados por alunos do ensino fundamental em aulas de ciências. Revista Brasileira de Pesquisa em Educação em Ciências, Belo Horizonte, v. 10, n. 2, 2010.

SASSERON, L. H.; CARVALHO, A. M. P. Alfabetização Científica: uma revisão bibliográfica. Investigações em Ensino de Ciências. Investigações em Ensino de Ciências. Porto Alegre, v. 16, n. 1 , p. $59-77,2011$. 
SASSERON, L. H. Alfabetização Científica, Ensino por Investigação e Argumentação: Relações Entre Ciências Da Natureza E Escola. Revista Ensaio, Belo Horizonte, v. 17, n. especial, p. 49-67, 2015

SILVA, E. F. A escrita no contexto da aula de ciências nos anos iniciais do ensino fundamental: relações Possíveis entre a alfabetização científica e alfabetização linguística. 2017. 152 f. Dissertação (Mestrado) - Departamento de Ciências da Educação, Universidade Estadual de Santa Cruz, Ilhéus, Bahia, 2017.

TREVISANI, J. A. Uma sequência de ensino investigativa sobre eletricidade nos anos iniciais do ensino fundamental: relevância do ensino deliberado na construção do conhecimento científico. 2019. 155 f. Dissertação (Mestrado) - Faculdade de Ciências e Tecnologia. Universidade Estadual Paulista, Presidente Prudente, 2019.

ZANON, D. A. V.; FREITAS, D. A aula de ciências nas séries iniciais do ensino fundamental: ações que favorecem a sua aprendizagem. Ciências \& Cognição. v. 10, p. 93 - 103, 2007.

ZERLOTTINI, K. G. Ensino de Ciências por investigação e produção de textos: um diálogo possível para a construção da autonomia de alunos das séries iniciais. 2017. $242 \mathrm{f}$. Dissertação (Mestrado) - Faculdade de Educação. Universidade Federal de Minas Gerais. Belo Horizonte, 2017.

ZOCOLER, F. A. S. O processo de ensino aprendizagem do discurso científico nos primeiros anos do Ensino Fundamental I. 2016. 209 f. Dissertação (Mestrado) - Programa de Pós Graduação em Ensino e História das Ciências e Matemática. Universidade Federal do ABC. Santo André, 2016.

ZOMPERO, A. F.; LABURU. C. E. Atividades Investigativas no Ensino de Ciências: Aspectos Históricos e Diferentes Abordagens. Ensaio - Pesquisa em Educação em Ciências, Belo Horizonte, v. 13, n. 3, p. 67-80, 2011. 